Journal of Contemporary Educational Research

Research Article

\title{
Study on the Development of Human Resources Services in Xinxiang
}

Yunmeng Sheng, Fuying Duan, Jinsuo He, Shuaiying Xie, Jinge Li, Yongsheng Zhang*

School of Economics and management, Henan Institute of Science and Technology, Xinxiang 453003, China

\begin{abstract}
With the continuous economic growth, human resources service industry also plays an important role in the economic development. In order to explore the development of human resources service industry in Xinxiang, based on a survey of more than 50 enterprises and organizations in Xinxiang, Xinxiang's human resources service industry has a bright future, however, there are still some problems in the aspects of enterprise scale, personnel skills and agglomeration management. Therefore, different countermeasures are put forward for different roles to solve the development obstacles and promote the development of industry agglomeration, building a new type of human resources to serve the ecological industry chain.
\end{abstract}

Key words: Xinxiang; Human resources services; Development

Publication date: October, 2020

Publication online: 31 October, 2020

* Corresponding author: Yunmeng Sheng, 270460660@qq.com

The Human Resources Service industry is an industry that builds communication channels for talents and employing units and provides services for talents. It has the characteristics of extensiveness and integration, infiltrating into different industries, the rapid development of human resource service industry not only benefits the rapid development of enterprises, but also promotes the rapid development of other industries and accelerates the development of local economy. Therefore, an in-depth investigation into the development of Human Resources Service Industry in Xinxiang, an analysis of the existing problems in human resources service industry, and an analysis of the current situation of Human Resources Service Industry in Xinxiang, will be of great help to promote the rapid development of human resources service industry and improve the relevant systems of human resources service industry, it has important theoretical and practical significance.

\section{Development Status and trend of Human Resources Service Industry in Xinxiang}

The overall development trend of Xinxiang's human resources service industry can be analyzed from the perspective of the development of enterprises and personnel, reflecting the overall development trend of human resources services industry.

The service object quantity is medium, has the bigger development space. In the survey data, $90 \%$ of the number of enterprise customers is concentrated in 300 or less, there are six enterprises more than 300 , the proportion of only $10 \%$. The number of service clients is less than 300, and more concentrated in $51--100$, accounting for $41 \%$, which shows that the number of service clients is still in a small range and has a large development space.

Younger age structure. In the survey data, the age of 21-30 accounted for $58 \%$ of the total population, 3140 years of age accounted for $39 \%$ of the total, over 50 years of age accounted for $3 \%$ of the total, thus, the proportion of employees in the age of 21-40 years of age accounted for $97 \%$, the trend towards the younger age of personnel in Xinxiang's human resources service industry, the development trend of human resources service industry enterprises and institutions in Xinxiang is good, and the size of the population is gradually expanding, the development of human resources service industry still has a lot of room for expansion. 
The quality of personnel is slightly higher than that of national counterparts. With the development of the industry, the number of employees has gradually increased, and the quality of personnel in the human resources service industry in Xinxiang has also been gradually improved. Personnel in the human resources service industry in Xinxiang have $77 \%$ of their educational qualifications at the undergraduate level or above, that is, two-thirds of the companies are staffed mainly by people with bachelor's degrees, which is slightly higher than the level of education in China in 2016-2017.

The trend of development of enterprises and institutions is good. In this survey, the majority of Xinxiang's human resources service organizations have been established for more than three years, more than half of the enterprises are in the period of development, a few are in the period of maturity, and there are almost no enterprises in the period of recession, according to the data of the development period of enterprises and institutions, the trend of the overall service enterprises and institutions in Xinxiang is good and has the potential to develop faster and better.

\section{Problems in the development of Human Resources Services in Xinxiang}

\subsection{The company is small, the staff professional ability is insufficient}

In the survey of the size of the organization, the size of the majority of the staff is in the range of less than 50 people $(60 \%)$ and $51-100$ people $(28 \%)$, not being able to provide adequate competitive protection to service enterprises or organisations, which indirectly affects the overall development of Human Resources Services in Xinxiang. This feature may be related to the economic development of Xinxiang, Xinxiang is not a first-and second-tier city, and Xinxiang has a number of universities, most of the service institutions are for students, the business population is limited to Henan Province.

Secondly, the prevention and handling of labor disputes $(25.98 \%)$, the recruitment of personnel (18.11\%) and the training of personnel $(15.75 \%)$ are the main difficulties in the investigation of difficulties faced by human resources service agencies, the lack of professionalism $(21.7 \%)$ of the staff of the service agency, the immature experience and methods of human resources service $(30 \%)$, and the lack of professional knowledge of labor relations and related aspects are often the important factors that lead the company into Labor disputes, it is the key to improve the skill quality of the whole staff of enterprises and institutions to solve the disputes and improve the skill level of the whole industry.

\subsection{Low agglomeration}

Agglomeration refers to the geographical distribution of industrial enterprises or institutions in a region. In this survey, it was found that the Human Resources Service Organizations in Xinxiang have shown a distinct feature: The service organizations are geographically dispersed, and there is only one key human resources industrial park in southern Xinxiang, there are many service institutions and enterprises, while around the major universities in the central and northern regions there are many small and mediumsized service institutions, which are distributed around the universities, it has caused great inconvenience to the overall management of Xinxiang's human resources service enterprises and institutions. If these small and medium-sized service enterprises and institutions can be clustered in the New East Human Resources Industrial Park, or the creation of a unified management platform through the Internet, not only to strengthen the management of the whole, but also to avoid uneven institutional development due to geographical location, to accelerate the overall rapid development of human resources services in Xinxiang.

\subsection{Limited business scope and low level of business}

As the country continues to deepen reform, the human resources service industry shows a trend of diversified development, but the survey of Xinxiang's human resources service companies and organisations shows that most are still at a low level of business. The business level of human resource service industry includes the type of business, the scope of region, the service population and so on. The business of Human Resources Service Organizations in Xinxiang is mainly labor dispatch (32.2\%), service outsourcing (23.3\%) , career recommendation (13.0\%), and other business is short-term part-time jobs for college students and social workers, most of the service organizations and service enterprises carry out recruitment, labor dispatch, job introduction, which is a common and single intermediary business, But in terms of talent assessment, training, occupation career planning, 
headhunting and other business development is less than the previous mentioned; Second, the business services sectors were mainly manufacturing $(21.0 \%)$ , catering (20.4\%), logistics (13.0\%) and household services $(11.7 \%)$, the areas of labor dispatch are mainly the manufacturing, logistics, and residential service industries in first-tier cities such as the business of internet information and construction industry with higher threshold is relatively less. The development of this kind of business level has a great obstacle to the overall human resource development of Xinxiang City.

\subsection{Technical limitations}

The key factors that restrict the success of the industry in the technical category mainly include: relationships and enterprise database $(75.4 \%)$, skilled employees (33.3\%) and technical level (8.8\%), enterprises should make use of "internet + " and other technologies to break the regional restriction and obtain more resources. For the service industry, the specialization of service type and service content is the key to the development of enterprises, the Enterprise pays attention to the brand effect in the development, provides the high level accurate service.

\section{Proposals to promote the healthy development of human resources services in Xinxiang}

\subsection{Firms on human resources services}

First of all, the service enterprise or institution shall improve the quality and skills of its personnel and expand its personnel size. For knowledge-intensive industries such as Human Resources Service Industry, which require high professional quality of personnel, the quality of personnel is related to the service level and future development of the organization, the problems existing in the operation and management of the organization, especially in the service experience and methods, management methods, planning and so on, can be effectively improved, and lack of professional knowledge to solve the problems in daily work, to improve the professional quality and skills of the staff through training, and to bring in high-quality personnel with human resources services through the personnel market of the human resources service industry or through the use of the Internet for personnel communication and exchange, build up a reserve army of excellent and high-quality talents. Second, service enterprises or institutions should enhance their own strength, in the business strength, to actively expand business or focus on a business. In the survey and analysis, most of the service enterprises or institutions only operate within the geographical scope of domestic or provincial operations, rarely expand their operations to the international scope, and the types of operations are also limited to recruitment, other operations, for example, the training and headhunting business is very small, which greatly affects the rapid development of Xinxiang's human resources service industry, so service enterprises or institutions should enhance their own strength and actively develop joint-level business.

\subsection{The New East Human Resources Industrial Park}

The New East Human Resources Industrial Park is an exemplary leader in human resources service industryin Xinxiang and should play a good leading role; To integrate the management of other small and mediumsized service enterprises and institutions in Xinxiang and to create an enabling environment for the overall development of the human resources services sector. The new East Human Resources Industrial Park is equipped with advanced information system, which can provide support and help to other service enterprises and institutions, solve the problems in time, and promote the centralization development of Xinxiang Human Resources Service Industry.

\subsection{Governments}

At present, the government is facing a low level of fractionalization in the Xinxiang's human resources service industry and a lack of innovation and development capability of enterprises. The government should actively guide the human resources service industry to carry out technological changes in the industry and build up a human resources information system. Good government guidance can play a vital role in the high-quality development of human resource service industry, and can effectively coordinate government guidance and market operation, and build a complete and well-structured market service system. The government should regulate licensing practices and access systems, guide industry development, crack down on dishonest and illegal practices, and strengthen penalties for illegal intermediaries, false recruitment and other violations of the legitimate rights and interests of enterprises and individuals, do a good job of market supervision to ensure the sound development of Human 
Resources Service Industry.

\section{References}

[1] Li CB. Research on the Development Bottleneck and Countermeasures of Regional Human Resource Service Industry -- A Case study of Jiangsu Province [J]. China Management Informationalization,2019, 22(6): 117-118.

[2] Tian YP. 40 years of human resources service industry innovation and development $[\mathrm{J}]$. China Human Resource
Development, 2019, 36(1):106-115.

[3] Wang R. Human Resources Service industry is ushering in a new Era [J]. China Human Resource Social Security,2018(9): 10.

[4] Huang R. The Opportunities and Challenges in the development of China's human resource Service Industry [J]. China Labor, 2018(3): 74-76.

[5] Lv XT. Research on the development of human resource service industry in henan province[J]. Fighting (martial arts science), 2014, 11(12): 115-118, 131. 